\title{
Common lower extremity injuries in female high school soccer players in Johannesburg east district
}

\author{
Primrose TS Mtshali (MSc Physio) ${ }^{1}$ \\ Nonceba P Mbambo-Kekana (PhD) ${ }^{1}$ \\ Aimee V Stewart (PhD) ${ }^{1}$ \\ Eustacius Musenge (MSc Med Bio+Epi) ${ }^{2}$ \\ ${ }^{1}$ Department of Physiotherapy, University of the Witwatersrand, Johannesburg \\ ${ }^{2}$ School of Public Heath, Agincourt Health and Population Unit, University of the Witwatersrand, Johannesburg
}

\begin{abstract}
Objectives. Soccer is one of the sports in South Africa which has seen an increase in the participation of youth and adult female players. The aim of this study was to determine point and 1-year prevalence, profile of injuries that affect female soccer players, associations between injuries and player position, age, use of equipment, frequency of play, and training duration.

Methods. A retrospective questionnaire-based descriptive survey of 103 first team high school female soccer players in the Johannesburg east district was conducted.

Results. The 1-year prevalence for the participants who reported injuries was $46 \%(N=47)$ and the point prevalence was $33 \%$ $(N=34)$. From these, a total of 78 and 42 injuries for the 1-year and point prevalence respectively were reported. An extended duration of skills $(p=0.0001)$ and fitness $(p=0.02)$ training in this population reduced the likelihood of incurring an injury. The older the participants, the more chance there was of sustaining injuries $(p=0.01)$. The participants who wore shin guards were less prone to shin/leg injuries $(p=0.01)$, the relative odds being 0.35 . The midfielders had more foot and toe injuries than the other players $(p=0.05)$. Starting age $(p=0.78)$, frequency of play $(p=0.83)$, wearing of shoes $(p=0.54)$ and stretching had no influence on injury. The knee and ankle were the main locations of injury, with defenders and midfielders mostly being injured.

Conclusion. A decrease in the duration of training for both skills and fitness and not wearing shin guards are risk factors for injury in female soccer players in high school. The profile of injuries and the risk factors determined from this study do not differ from the studies done in male adolescent and adult soccer players.
\end{abstract}

\section{CORRESPONDENCE:}

Ms Siphe Mtshali

Department of Physiotherapy

University of the Witwatersrand

7 York Road

Parktown, 2193

Tel: 27117173702

Fax: 27865534766

E-mail:siphe.mtshali@wits.ac.za

\section{Introduction}

Soccer is one of the most popular sports in the world, and has been played in many countries of the world, including South Africa, for more than 100 years. ${ }^{1}$ Currently there are 208 member associations of FIFA. ${ }^{1}$ The popularity of soccer in South Africa is seen in the township streets, where it is commonly played by boys. However, more recently girls can also be seen playing soccer in the streets. Although there has been organised soccer for young players over a decade, with leagues being played annually, the emphasis has mainly been on male players.

As the number of females participating in sports has increased, so has the necessity to understand the effect of female growth and development on participation, athletic ability and injury patterns. ${ }^{2-4}$ However, there are limited data on female soccer players, as most studies on soccer concentrate on male soccer players. ${ }^{5-7}$ Although participation in youth soccer for girls has started to increase in the past few years in South Africa, no studies have been published to determine the profile of injuries in adolescent girls. Because of the limited information on injuries in female soccer players, it cannot be stated whether or not characteristics and causes of injuries are similar or vary substantially from those previously reported for male players. ${ }^{6}$ As a contribution to learning more about injuries associated with female soccer players, this study was conducted to establish the prevalence and injury profile of lower extremity injuries in female high school soccer players.

\section{Methodology}

This study was conducted using a retrospective descriptive questionnaire-based design. Out of 42 high schools from Johannesburg east district recruited to participate, only 13 schools had female soccer teams. Data were collected during the schools' soccer season from May to August 2006. This included information from the 2005 season. Permission to conduct the study was granted by the Human Research Ethics Committee from the University of the Witwatersrand, Gauteng Department of Education and schools that participated in the study. Informed consent and assent was signed by parents/guardians and participants before the questionnaires were administered. The questionnaire was developed and piloted for validity; it included point and 1-year prevalence, profile of injuries, ${ }^{8}$ player position, age, use of equipment, frequency of play, and training duration. The questionnaires were distributed by the researcher during training sessions and collected again immediately after the training session. 


\begin{tabular}{|lll|}
\hline \multicolumn{2}{l|}{ Table I. Use of equipment } \\
\hline Equipment & $\mathbf{N = 1 0 3}$ & $\%$ \\
\hline Shoes & & \\
$\quad$ Shoes with studs & 83 & 81 \\
$\quad$ Shoes without studs & 18 & 18 \\
$\quad$ Bare feet & 2 & 2 \\
Shin guards & 54 & 52 \\
(N is the total number players.) & & \\
\hline
\end{tabular}

Table III. Association between duration of training and injury for point prevalence

\begin{tabular}{lccll}
\hline $\begin{array}{l}\text { Duration of training } \\
\text { (minutes) }\end{array}$ & $\begin{array}{l}\text { Skill } \\
\mathbf{N}=\mathbf{3 2}\end{array}$ & \multicolumn{3}{l}{$\begin{array}{l}\text { Fitness } \\
\mathbf{N}=\mathbf{3 3}\end{array}$} \\
30 & 0 & 0 & & \\
45 & 19 & 59 & 6 & 18 \\
60 & 8 & 25 & 5 & 15 \\
90 & 5 & 16 & 22 & 67 \\
$p$-value & 0.0001 & & 0.02 & \\
(N is the number of participants involved skills/fitness training.) & &
\end{tabular}

Several statistical procedures were used in the analysis, namely Fischer's exact test, student $t$-test and logistic regression. To find associations between pairs of categorical variables Fischer's exact test was used. The student's $t$-test was used to test for differences between two groups of Gaussian numerical variables. Univariate as well as multivariate regressions were done using a logistic regression. These calculations were done to find association between the factors (age, location of injuries, and frequency of play, training duration, stretching and use of soccer boots and shin guards (equipment) with the dichotomous response variable. Statistical significance was accepted at the $5 \%$ level of significance.

\section{Results}

\section{Demographic data}

Nine schools participated in the study as the other four schools that offered girls' soccer were not currently active in soccer during the study. The schools had 11 players and 4 reserve players $(N=135)$ in the first team and those with signed consent were given questionnaires $(N=103)$. The sample size of 103 represents $76 \%$ of the total sample.

The average age of the participants was $16.1 \pm 1.4$ years and they started playing soccer when they were $12.1 \pm 2.7$ years old. The distribution of player position was as follows: goalkeeper (8\%), defenders (41\%), midfielder (33\%) and strikers (18\%). The equipment used by the players is illustrated in Table I.

\begin{tabular}{|c|c|c|c|c|}
\hline \multirow[t]{2}{*}{ Location of injuries } & \multicolumn{2}{|c|}{$\begin{array}{l}\text { One-year } \\
\text { prevalence } \\
(2005)\end{array}$} & \multicolumn{2}{|c|}{$\begin{array}{l}\text { Point } \\
\text { prevalence } \\
(2006)\end{array}$} \\
\hline & $N=78$ & $\%$ & $N=42$ & $\%$ \\
\hline Hip joint & 5 & 6 & 0 & \\
\hline Groin muscle & 2 & 3 & 0 & \\
\hline Quadriceps muscle & 5 & 6 & 0 & \\
\hline Hamstrings muscle & 5 & 6 & 0 & \\
\hline Knee joint & 19 & 24 & 12 & 29 \\
\hline Leg bone & 7 & 9 & 7 & 17 \\
\hline Calf muscle & 7 & 9 & 0 & \\
\hline Ankle joint & 18 & 23 & 17 & 41 \\
\hline $\begin{array}{l}\text { Foot and toes } \\
\text { ( } N \text { is number of injuries.) }\end{array}$ & 10 & 13 & 6 & 14 \\
\hline
\end{tabular}

In this study, the participants $(77 \%)$ played one match per week whereas the training was mainly twice a week. During training $91 \%$ of the participants did skills training and $96 \%$ did fitness training. The duration of training was on average 45 - 60 minutes.

\section{Injuries}

The operational definition for injury used in this study was, as defined by Fuller et al., ${ }^{8}$ as 'any physical complaint sustained by a player that results from a football match or football training, irrespective of the need for medical attention or time-loss from football activities'.

Prevalence is the measure of injuries in a population at a given point in time (point prevalence) and can also be measured over a period of time (period prevalence). ${ }^{9}$

The 1-year (2005) prevalence of participants injured was $46 \%$ $(N=47)$ and the point (2006) prevalence of participants injured was $33 \%(N=34)$.

\section{Location of injuries}

Seventy-eight injuries were reported for 1-year prevalence and point prevalence reported 42 injuries. The participants reported more than one injury. Of all the reported injuries the knee and ankle were the most injured areas (Table II).

\section{Associations of injuries of various factors and injury Association between age and injury}

For the point prevalence, current age was associated with injury $(p=0.01)$, meaning that the older the player the more likely they were to be injured. There was no association between the age of starting to play soccer and injury for point prevalence.

\section{Table IV. Association between location of injuries and player position (point prevalence)}

\begin{tabular}{|c|c|c|c|c|c|c|c|c|c|}
\hline \multirow[t]{2}{*}{ Point prevalence } & \multicolumn{2}{|c|}{ Goalkeeper } & \multicolumn{2}{|c|}{ Defender } & \multicolumn{2}{|c|}{ Midfielder } & \multicolumn{2}{|c|}{ Striker } & \multirow[t]{2}{*}{$p$-value } \\
\hline & $N$ & $\%$ & $N$ & $\%$ & $N$ & $\%$ & $N$ & $\%$ & \\
\hline Knee joint & 1 & 8 & 6 & 60 & 2 & 17 & 3 & 25 & 0.28 \\
\hline Leg bone & 1 & 14 & 3 & 43 & 2 & 29 & 1 & 14 & 0.29 \\
\hline Ankle joint & 0 & & 8 & 47 & 6 & 36 & 3 & 18 & 0.36 \\
\hline Foot and toes & 0 & & 1 & 17 & 4 & 67 & 1 & 17 & 0.05 \\
\hline
\end{tabular}




\begin{tabular}{|c|c|c|c|c|}
\hline \multicolumn{5}{|l|}{ Variable } \\
\hline One-year prevalence & Odds ratio & Standard error & 95\% Confidence level & $p$-value \\
\hline Starting age & 0.98 & 0.92 & $0.85-1.13$ & 0.78 \\
\hline Current age & 0.88 & 2.28 & $0.67-1.16$ & 0.37 \\
\hline \multicolumn{5}{|l|}{ Training } \\
\hline Skill & 0.64 & 0.7 & $0.16-2.55$ & 0.53 \\
\hline Fitness & 0.26 & 0.17 & $0.03-2.64$ & 0.26 \\
\hline \multicolumn{5}{|l|}{ Duration of training } \\
\hline Skill & 1.03 & 0.18 & $0.72-1.47$ & 0.86 \\
\hline Fitness & 1.24 & 0.18 & $0.86-1.77$ & 0.25 \\
\hline Matches per week & 0.94 & 0.29 & $0.53-1.6$ & 0.83 \\
\hline Player position & 0.75 & 0.23 & $0.48-1.18$ & 0.2 \\
\hline Shoes & 1.36 & 0.5 & $0.50-3.68$ & 0.54 \\
\hline Shin guards & 0.35 & 0.41 & $0.16-0.79$ & 0.01 \\
\hline
\end{tabular}

\begin{tabular}{|c|c|c|c|c|}
\hline \multicolumn{5}{|l|}{ Variable } \\
\hline Point prevalence & Odds ratio & Standard error & $95 \%$ Confidence level & $p$-value \\
\hline Starting age & 1.04 & 0.07 & $0.9-1.21$ & 0.6 \\
\hline Current age & 0.64 & 0.19 & $0.4-0.9$ & 0.01 \\
\hline \multicolumn{5}{|l|}{ Training } \\
\hline Skill & 3.14 & 1.12 & $0.35-28.1$ & 0.31 \\
\hline Fitness & 1000 & 546 & $0.001-1000$ & 1 \\
\hline \multicolumn{5}{|l|}{ Duration of training } \\
\hline Skill & 1.06 & 0.21 & $0.7-1.6$ & 0.8 \\
\hline Fitness & 0.51 & 0.3 & $0.3-0.9$ & 0.02 \\
\hline Matches per week & 0.83 & 0.38 & $0.4-1.7$ & 0.62 \\
\hline Player position & 0.9 & 0.24 & $0.55-1.45$ & 0.65 \\
\hline Shoes & 0.9 & 0.52 & $0.32-2.45$ & 0.82 \\
\hline Shin guards & 0.82 & 0.44 & $0.35-1.94$ & 0.65 \\
\hline
\end{tabular}

\section{Association between duration of training and injury}

More injuries were reported as the duration of skills training increased (for 1-year prevalence), but this was not a significant association $(p=0.06)$. The point prevalence of injuries was highest when players did skills training for 45 minutes $(p=0.0001)$ and fitness training for 90 minutes $(p=0.02)$. Players who trained for 30 minutes or less did not report any injuries (Table III).

\section{Association between location of injuries and player po- sition}

There was no association between player position and location of injury for the 1-year prevalence; however there was an association in point prevalence results where the midfielders had $67 \%$ toe and foot injuries and were most likely to incur foot and toe injuries $(p=0.05)$ compared with other positions (Table IV).

\section{Extrinsic risk factors associated with injuries}

Tables $V$ and VI summarise the risk factors associated with injury for point and 1-year prevalence. The odds ratios (OR) in the tables illustrate the protectiveness of the different variables against injury. The results (Table $\mathrm{V}$ ) show that shin guards were associated with a reduced the risk of having an injury $(\mathrm{OR}=0.35)(p=0.01)$.

The age of the players was associated with injury, with older players having a greater chance of being injured $(O R=0.64)(p=0.01)$. The duration of fitness training reduced the risk of injury if fitness training was more than 45 minutes $(\mathrm{OR}=0.51)(p=0.02)($ Table $\mathrm{VI})$.

\section{Discussion}

Although studies ${ }^{5-7,10-12}$ have been done mainly in male adolescent soccer players, the results are similar to the results of this study. This study reports the number of injuries as being between $38 \%$ and $46 \%$. This is however lower than the rate of injury in the adult professional female soccer players, which ranges from $55 \%$ to $70 \% .{ }^{13,14}$ The difference between adolescent and adult female studies may be attributable to the level of exposure, where the professional players have an increased number of training sessions per 1000 hours and up to two matches per week which are of a longer duration (90 minutes). In this study, training and matches were played mainly once a week and the duration of matches was 60 minutes. 
The presence of more knee and ankle injuries may be attributed to the skill of cutting, jumping and landing, which is different in girls. When comparing adolescent females and males during unanticipated cutting manoeuvres, females had a greater abduction of the knee; this in turn increases the genu valgus, which may be a risk factor for knee injuries, specifically the anterior cruciate ligament. ${ }^{15}$ The ankle is the main point of contact during soccer matches and training, therefore it is most likely to incur more injuries. The higher number of knee and ankle injuries in this study is consistent with a number of prospective studies where the knee was the most commonly injured area followed by ankle injuries in a female population. $4,12,14,17$

The exposure level in this study also contributed to the higher rate of minor injuries which were reported. Other studies on high school soccer players ${ }^{11,12}$ also report that there are more minor injuries associated with exposure level. Foul play may contribute to incidence of severe injuries because of poor application of the rules of the game and poor refereeing. In addition, severe injuries may occur as a result of poor pitch surfaces. ${ }^{2}$

No injuries were reported for the shorter (30 minutes or less) duration of skills and fitness training in this study and most injuries occurred after skills training for 45 minutes. Thereafter there was a downward trend in the number of injuries as the duration of skills training increased (Table III). Although there was statistical significance in the duration of fitness training $(p=0.02)$ and injury, it was difficult to determine the mechanism of injury. It may be speculated that as skill and fitness improves so does the confidence of players in handling opponents during matches. The decrease in the number of injuries as the duration of skills training increases in this study is in contrast with the study on male players, ${ }^{10}$ where there was an increase in the number of injuries in players with low skill level.

The defenders $(41 \%)$ and midfielders $(33 \%)$ were the players most commonly injured in this study. This can be understood because soccer is more robust in midfield and strength of the lower limbs is required to win the ball. The defenders put their lower extremities 'on the line' when defending a ball, hence they are most likely to be injured. The midfielders were found to be more likely to incur foot and toe injuries $(p=0.05)$ compared with other positions. Tackling and running during matches for players in the midfield positions could be associated with injuries. Although other studies report that defenders and midfielders are injured more in relation to other positions of play, ${ }^{7,10,19}$ the location of injuries was not related to player position.

In this study there was a small number of leg or shin injuries $(9 \%)$ for 1-year prevalence (Table II), but the results show that wearing shin guards (Table $V$ ) reduces the risk of shin injuries $(p=0.01)$. The likelihood of reducing an injury by wearing skin guards in this study (Table V) was 65\% (OR=0.35). Contact with another player may be the cause of acute shin injuries rather than overuse injuries. Lilley et al. ${ }^{18}$ reported ankle injuries to be $24 \%$ followed by shin injuries at $18 \%$ as being the highest percentage of injuries in their retrospective study of an adolescent soccer population, but it was not clear whether the participants were wearing shin guards or not. Therefore it is not possible to compare the two studies. However, not wearing shin guards has been shown to have a direct link to leg injuries. ${ }^{10}$
In conclusion the results of this study show that injuries occur mainly to the knee and ankle, but factors contributing to the injuries need to be investigated further. The 1-year and point prevalence data in this study were within the ranges reported in other similar studies. This study showed an association between various risk factors (shin guards, current age, and duration of fitness training) and injury. However, these results need to be viewed with caution because of the small sample size. The practical applications of these data are that training on proper skills and fitness programmes for school coaches or educators should be implemented to reduce the number of injuries. Furthermore, it may be recommended that shin guards should be worn to reduce the risk of leg injuries.

\section{REFERENCES}

1. www.fifa.com (accessed 12 May 2009).

2. Goga IE, Gongal P. Severe soccer injuries in amateurs. Br J Sports Med 2003;37:498-501.

3. Hewett TE. Neuromuscular and hormonal factors associated with knee injuries in female athletes: strategies and prevention. Sports Med 2000;29(5):313-327.

4. Odion AA. Injury pattern of the national female soccer team of Nigeria (The Falcons) from 1997-1999. Journal of the Nigerian Medical Rehabilitation Therapists 2001;6(1):11-16.

5. Hutchinson MR, Nasser R. Common sports injuries in children and adolescents. Medscape General Medicine 2000; 2(4): (http://www.medscape. $\mathrm{com} /$ viewarticle/408524)

6. Junge A, Dvorak J. Soccer injuries: A review on incidence and prevention. Sports Med 2004;34(13):929-938.

7. Kucera KL, Marshall SW, Kirkendall, Marchak PM, Garrett Jr WE. Injury history as a risk factor for incident injury in youth soccer. Brit J Sports Med 2005;39:462-466.

8. Fuller CW, Ekstrand J, Junge A, et al. Consensus statement on injury definitions and data collection procedures in studies of football (soccer) injuries. Clin J Sport Med 2006;16(2):97-106.

9. Friis R, Sellers T. Epidemiology for public health practice. Second edition. Gaithersburg, Maryland: Aspen Publish, Inc., 1999.

10. Dvorak J, Junge A. Football injuries and physical symptoms: Review of literature. Am J Sports Med 2000;28(5):S3-S9.

11. Le Gall F, Carling C, Reilly T, Vandewalle H, Church J, Rochcongar P. Incidence of injuries in elite French youth soccer players: A ten-season study. Am J Sports Med 2006;34(10):1-11.

12. Powell JW, Barber-Foss KD. Sex related patterns among selected high school sports. Am J Sports Med 2000;28(3):385-391.

13. Faude O, Junge A, Kinderman W, Dvorak J 2005 Injuries in female soccer players: A prospective study in the German National League. Am J Sports Med 2005;33(11):1694-1700.

14. Giza E, Mithofer K, Farrell $L$ Zarins B, Gill T. Injuries in women's professional soccer. Br J Sports Med 2005;39:212-216.

15. Ford KR, Meyer GD, Toms HE, Hewett TE. Gender specific differences in the kinematics of unanticipated cutting in young athletes. Med Sci Sports Exerc 2005;37(1):124-129.

16. Emery CA, Meeuwisse WH, Hartmann SE. Evaluation of risk factors for injury in adolescent soccer: Implementation and validation of an injury surveillance system. Am J Sports Med 2005;33(12):1882-1891.

17. Emery CA, Meeuwisse WH. Risk factors for injury in indoor compared with outdoor adolescent soccer. Am J Sports Med 2006;34(10):1636-1644.

18. Lilley K, Gass E, Locke S. A retrospective injury analysis of state representative female soccer player. Phys Ther 2002;3:2-9.

19. Van Heerden HJ. The evaluation of injury in junior soccer players. S Afr J Sports Med 1992;7(2):3-6. 